\title{
OPTIMIZATION OF MAIN BOILER PARAMETERS USING SOFT COMPUTING TECHNIQUES
}

\author{
P. Hari Krishnan ${ }^{1}$, Prathyusha $\mathbf{S}^{2}$ \\ ${ }^{1}$ Assistant Professor, Department of EEE, Anna University, Regional Centre Coimbatore, Tamil Nadu, India \\ ${ }^{2} P G$ Scholar, Department of C\&I, Anna University Regional Centre Coimbatore, Tamil Nadu, India
}

\begin{abstract}
In most of the large scale industrial applications, the controlling and optimization of the parameters has to be done efficiently so as to attain the smooth operation of the industry. In this paper, the main control parameters of any process industries such as level of feed water, steam temperature and flow of steam were optimized by using ANFIS with PID controller. An ANFIS system is an adaptive network in which each node perform a particular function with respect to the incoming signals, with parameters are updated according to the given training data and a gradient-descent learning procedure. The simulation is done in MATLAB software. By using Neuro-fuzzy controller with PID, the transient response was improved and the settling time was reduced.
\end{abstract}

Keywords: ANFIS, PID Controller, MATLAB, Level, Temperature, Flow

\section{INTRODUCTION}

In large scale applications, the boiler is an essential part that generates steam at particular temperature which is used for process and environmental heating. Thus, it is important to optimize the main parameters of the boiler such as level of feed water, steam temperature and the flow of the steam. Optimization of the above parameters reduces the running costs and improves site operations. For the optimization, it is necessary to consider both the steam and feed water system. At present, PI (proportional-integral) Controllers have been commonly used in the process industries. Because of the uncertainties, a good control scheme is not necessary, but a well tuned PID controller is efficient. Conventional controllers like PID controllers were used in the industries. The proportional action adjusts the controller output with respect to the error, the integral eliminates the offset and the future is anticipated by derivative action.

The introduction of artificial intelligence itself made the system close to the human intelligence. The human expert knowledge is based on the heuristic information gained in the relation to the plant operation. Its inherent vagueness gave a powerful tool for the modelling of a complex system. Neurofuzzy is a combination of neural network and fuzzy system resulting in a hybrid system. It is capable of reasoning and learning in an uncertain and imprecise environment. Neurofuzzy is said to be a universal estimator. The system will be more precise when neuro-fuzzy is used, because it contains human like reasoning style and learning and connection structure also, thereby utilizing the advantages of both neural network and fuzzy system. The ANFIS is the abbreviated form of Adaptive Neuro-Fuzzy Interference System. The performance of this method is similar to both ANN (Artificial
Neural Network) and FL (fuzzy logic). In both ANN and FL case, the inputs are passed through the input layer (by input membership function) and the output is obtained from the output layer (by output membership functions). ANFIS performs the membership function parameter adjustments. ANFIS provides a method for the fuzzy modelling procedure to learn the information about given data to compute the membership function parameters that best allow the associated fuzzy interference system to track the given input/output data. This is used for controlling of MISO (Multiple-Input-SingleOutput) systems. In this paper, the process optimization uses the advantages of fuzzy system and adaptive learning system of ANFIS with the PID controller.

\section{SYSTEM REQUIREMENTS}

When PID controller is used, there occurs a high over shoot and high settling time. In order to reduce these high overshoot and high settling time, ANFIS with PID controller is used.

\subsection{Block Diagram}

The block diagram consists of an ANFIS and PID controller connected with the process. ANFIS will train the values by using fuzzy interference system. The trained values are given to the PID controller for the proper optimization of the process parameters. 


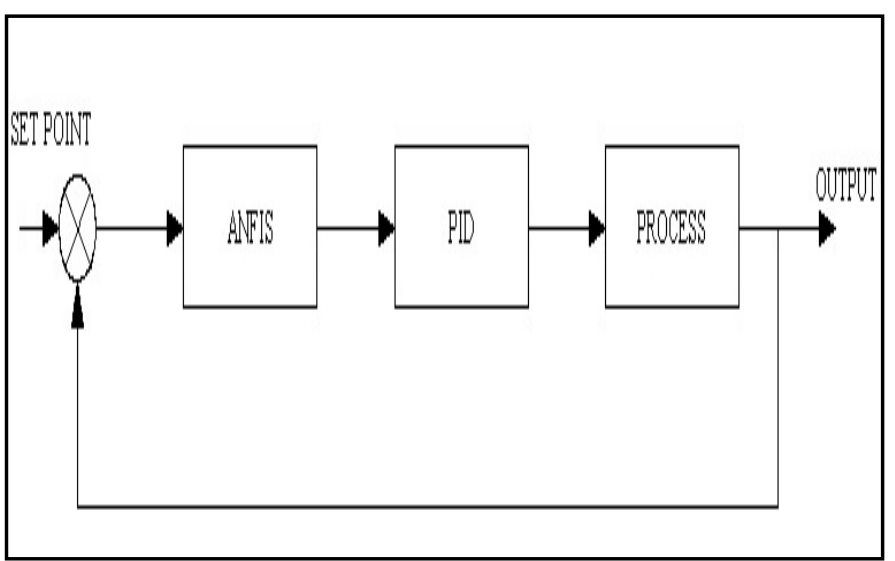

Fig -1: Block Diagram using ANFIS with PID controller in the process

The feedback from the process is compared with the set point value and the error value generated is trained by using ANFIS tool and given to the PID controller for the optimization of the process. The Figure 1 shows the block diagram using ANFIS with PID controller.

The basic architecture of ANFIS is shown in Fig.2. The steps involving the change from classical fuzzy logic to the neuroadaptive learning approach is described as below.

- Determine initial fuzzy structure

- Initialize the fuzzy structure to meet desired performance by using ANFIS and thus update the fuzzy parameters

- Under different operating conditions, the action is evaluated

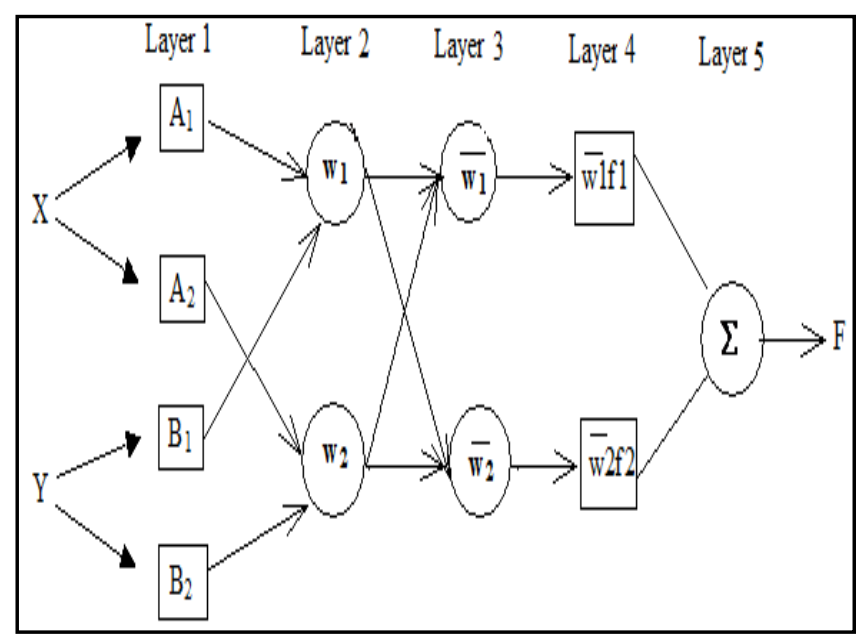

Fig -2: Basic Architecture of ANFIS

Membership function parameters can be chosen automatically using ANFIS tool in MATLAB. Using ANFIS, a fuzzy interface system ANFIS, a fuzzy interface system can be applied for which a collection of input/output data parameters sets are present. The structure of ANFIS is shown in figure 3.

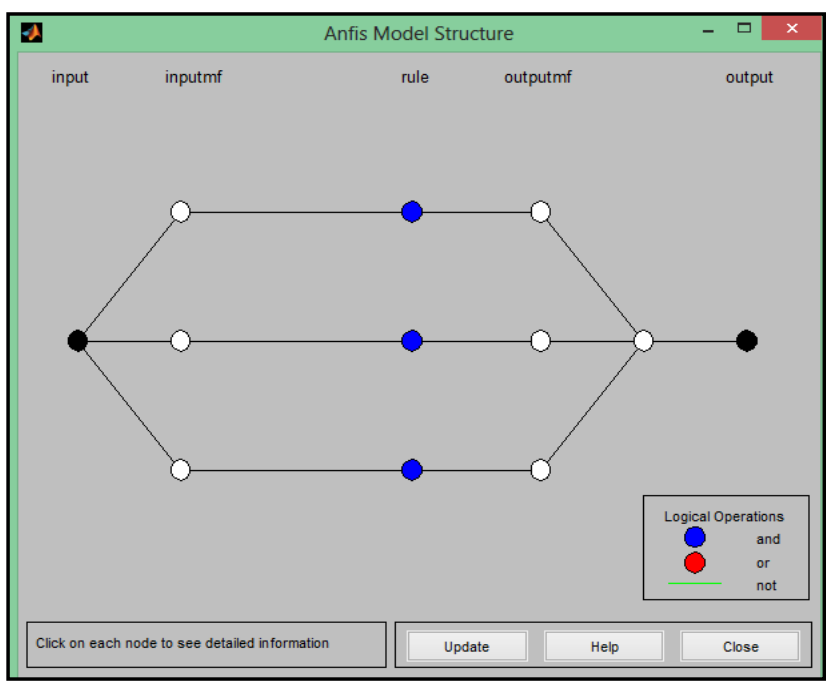

Fig -3: Structure of ANFIS

The steps to create an ANFIS tool, to train the values are explained as below.

- Data is loaded, plotted and cleared

- The initial FIS structure is generated or loaded

- $\quad$ FIS is trained

- $\quad$ The trained FIS is validated

\subsection{Boiler}

A boiler is an enclosed vessel that provides a means for combustion of heat to be transferred into water. The water or steam under pressure is then usable to transferring the heat for the steam requirements of process industries or for power generation.

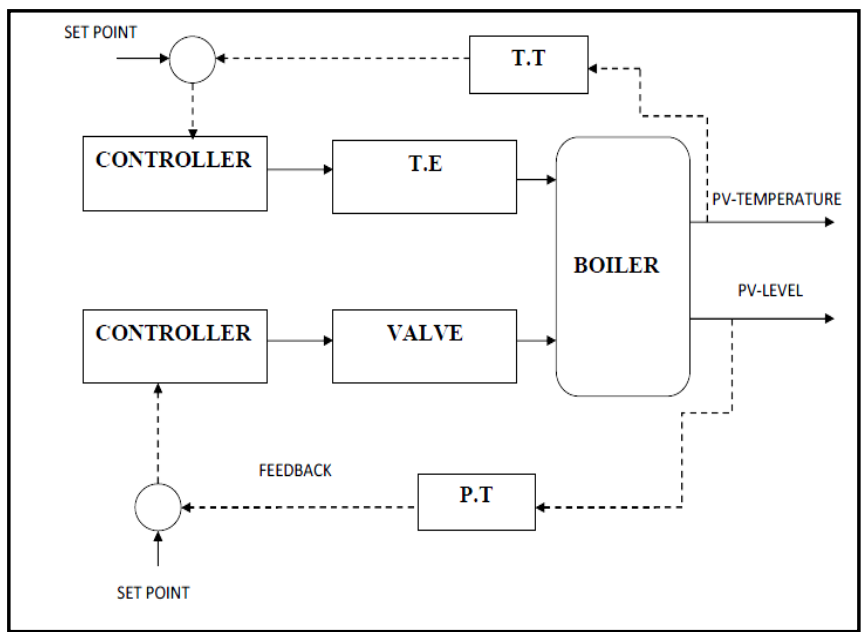

Fig -4: Block Diagram of Boiler describing the temperature and feed-water level to be optimized 
The block diagram is shown in figure 4. The basic block diagram consists of two controllers to control the valve ad the temperature element connected to control the valve and the temperature element connected to the process i.e., boiler. The level of the boiler is determined using the pressure transmitter and compared with the set point and then the error generated is fed back to the controller for controlling the valve. For temperature control, the same process goes on. The temperature in the boiler is transmitted using temperature transmitter and compared with the set point. The error generated is controlled using the temperature controller.

The boiler is to be controlled due to the following reasons.

- Increase uptime and availability

- Reduce flue gas emissions

- Maintain boiler safety

- Control operating costs

In this paper the main parameters to be optimized using soft computing techniques were feed water level, steam flow and the steam temperature.

\subsection{Level Control}

In the controlling of boiler- turbine unit, it is necessary to meet the requirement of water in the steam drum to a desired level, in order to prevent the drum over heating of steam line flooding. The drum level should be controlled to limits specified by the manufacturer. If the limit of level exceeds, water will be carried over to the super-heater or the turbine may cause damage resulting in the increase in the maintenance cost. Again, if it is low below a certain prescribed level, tubes are over-heated and thus causes rupture in the tubes. This causes serious accidents and even causes death.

To ensure good quality steam which is produced safely and efficiently, the level of the boiler is to be controlled carefully. The heat for generating steam is produced by the combustion of fuel in the furnace. The heat generated is transferred to water in the boiler furnace. Thus the steam is produced under a certain pressure. If the boiler works with insufficient water, explosion may take place. For this reason, controlling of boiler is required to (a) monitor and control the water level and (b) detect if the water reaches less than the desired point and takes appropriate action.

\subsection{Temperature Control}

The steam temperature has to be kept under control in order to avoid the excess usage of feed water in the boiler. Also, the steam temperature should be in the desired range.

The temperature control system consists of a process, a temperature transducer, feedback controller and a temperature element. The temperature transmitter transmits the temperature from the process, which is then compared with the set point value. The error generated is then given to the controller. The temperature element produces an appropriate action to minimize the error value. Temperature requirements for heating water vary with the outdoor temperature. While considering the controlling of steam temperature, the surrounding temperature is considered.

\subsection{Flow Control}

The flow control loops can be in the flow into the boiler burners, burner draft airflow, feed water into the boiler or steam out of a boiler. The feed water flow can be controlled, when the feed water level is being controlled. In this paper, the steam flow is being controlled by using ANFIS with PID controller. Control valve is the control element of the flow control system. The flow control system consists of a process, a flow transducer, feedback controller and a control valve. From the process, the flow rate is measured by using a flow transducer which is fedback to the controller. This is compared with the set point value and according to the error the control element produces an action.

\section{RESULTS}

The simulation of the optimization of the boiler parameters such as level of feed water, the steam temperature and the flow rate of steam were done in MATLAB software. The name MATLAB stands for Matrix Laboratory. It is high performance software for computation. The model was created in the Simulink of MATLAB.

The results obtained for the simulation block diagram were shown in Fig 5 to 7.

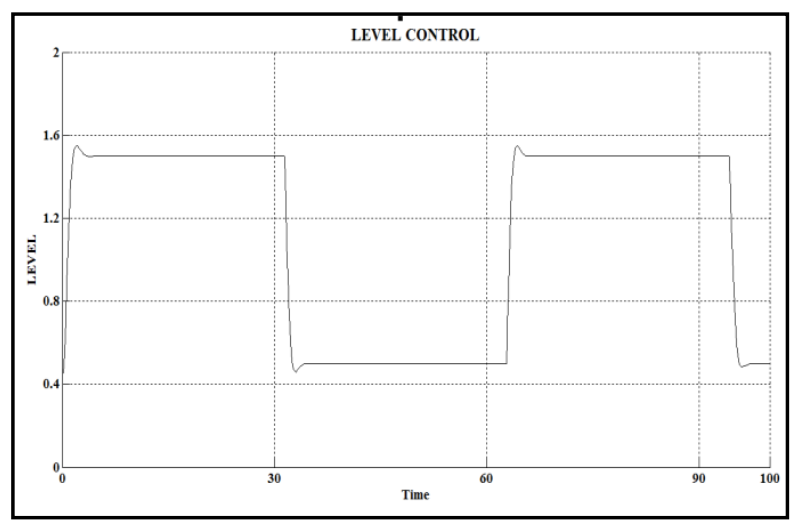

Fig -5: Output Waveform of Level Control

The level of the liquid in the boiler furnace was controlled in between the set point values, 0.5 to 1.5 with an overshoot. The flow of steam from the boiler has been settled at $1 \mathrm{~m}^{3} / \mathrm{s}$. The steam temperature reaches $150^{\circ} \mathrm{C}$. 


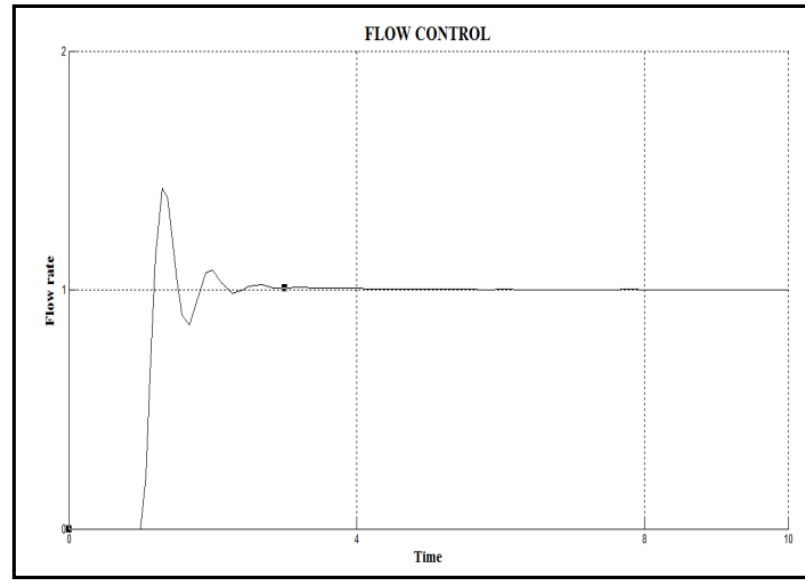

Fig -6: Output Waveform of Flow Control

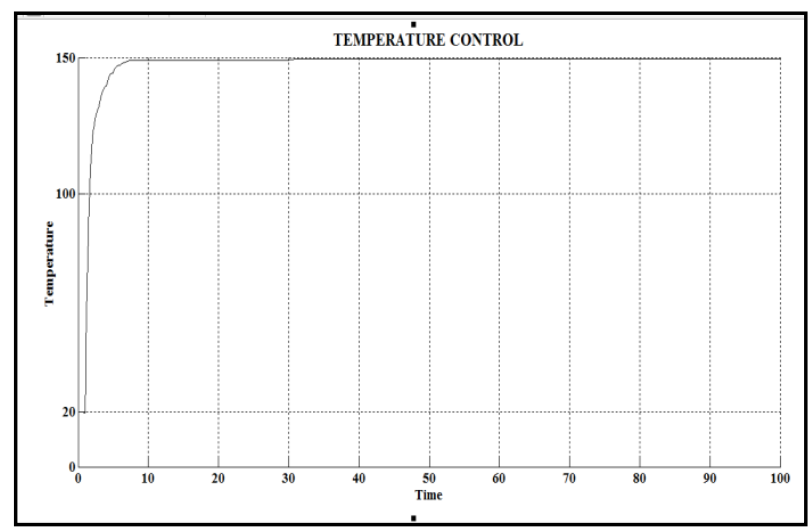

Fig -7: Output Waveform of Temperature Control

The set point for the system for controlling level is 0.5 to 1 . The output is obtained in between those values with little overshoot showing that it is beings controlled in the range of given set point as shown in Fig.5.

The flow rate has to be controlled at $1 \mathrm{~m}^{3} / \mathrm{s}$. The set point is given as $1 \mathrm{~m}^{3} / \mathrm{s}$. The peak overshoot obtained is 1.4 as shown in Fig.6. The temperature has to be controlled to the set point value of $150^{\circ} \mathrm{C}$. The simulation is done by considering the outside environment temperature which is set to $20^{\circ} \mathrm{C}$. Hence, it is shown in Fig 7, in which the initial point starts at 20. It is done with the help of ANFIS with PID controller.

\section{CONCLUSIONS}

In this paper, the main parameters are optimized by using ANFIS with PID controller. The main parameters include the level of the feed water in the boiler, the steam temperature and the flow of steam. The level has been optimized in between 0.5 and $1.5 \mathrm{~m}$, the flow of steam is controlled to $1 \mathrm{~m}^{3} / \mathrm{s}$ with an overshoot of 1.4, and the temperature of the steam is controlled to a constant value of $150^{\circ} \mathrm{C}$, also considering the outside temperature. The settling time of steam flow rate, the temperature and the feed water control are reduced. This result shows a significant improvement in maintaining the performance over a range by using ANFIS with PID controller. The transient response was improved and the settling time has been reduced.

\section{ACKNOWLEDGEMENTS}

I would like to record my special thanks and deep sense of indebtedness and hearted gratitude to my gifted guide Mr. P. HARI KRISHNAN, M.E., Assistant Professor, Anna University, Regional Centre Coimbatore, for his active involvement, encouraging, caretaking and valuable suggestions in all way and guiding me in my project. I express my heartfelt thanks to Management and Faculty Members of EEE Department, Anna University, Regional Centre Coimbatore, for her encouragement in this project.

I also extend my sincere thanks to my parents and entire friends to encourage and who have render their valuable help in this project.

\section{REFERENCES}

[1]. Rahul Malhotra, Rajinder Sodhi, "Boiler Flow Control Using PID and Fuzzy Logic Controller," IJCSET, Vol 1, Issue 6,315-319 July 2011.

[2]. Sudath R. Munasinghe, Min- Soeng Kim and Ju- Jang Lee, "Adaptive Neurofuzzy Controller to Regulate UTSG Water Level in Nuclear Power Plants", IEEE Transactions On Nuclear Science, Vol 52, No.1, February 2005.

[3]. Chao-Ying Liu, Xue-Ling Song, Ying-Cai Sheen, ZheYing Song, "Control System Design of Heat Exchange Station based on Fuzzy technology," Proceedings of the Fifth International Conference on Machine Learning and Cybernetics, pp. 380-384, 2006.

[4]. Abdelelah Kidher Mahmood, Hussam Hamad Taha., "Design Fuzzy Logic Controller for Liquid Level Control, International Journal of Emerging Science and Engineering (IJESE), ISSN: 2319-6378, Volume- I Issue-II, September 2013.

[5]. X. - J. Liu and C. W. Chan, "Neuro- Fuzzy Generalized Predictive Control of Boiler Steam Temperature" IEEE transactions on Energy Conversion, Vol. 21, No 4, December 2006

[6]. Andris Sniders, Toms Komass, "Simulation Of MultiLink Invariant Control System For Steam Boiler" Engineering For Rural Development, Jelgava, 23.-24.05.2013

[7]. Navratil. P and Balate. J "Simulation of control of multivariable control loop : Steam Turbine" Issn 1726 - 4529 Vol $2,53-65$

[8]. Namrata Dey, Ria Mandal, and M Monica Subashini, "Design and Implementation of a Water Level Controller using Fuzzy Logic," International Journal of Engineering and Technology, ISSN : 0975-4024, Vol 5 No 3, pp. 2277-2285, Jun-Jul 2013. 
[9]. Yifeng Wu, Xiaoqi Lin "Research of Boiler Fault Diagnosis Based on Fuzzy Neural Network"

[10]. K. Ghousiya Begum, D.Mercy, H. Kiren Vedi, and M. Ramathilagam, "An Intelligent Model Based Level Control of Boiler Drum" International Journal of Emerging Technology and Advanced Engineering, ISSN 2250-2459, ISO 9001:2008 Certified Journal, Volume 3, Issue 1, January 2013

[11]. Tatang Mulyana, Mohamad Nor Mohd Than, Dirman Hanafi and Afrodi Ali, "Digital Control Design for the Boiler Drum" Journal of Mechanics Engineering and Automation 1 392-397 October 2011.

[12]. Morteza Mohammadzaheri, Ali Mirsepahi, Orang Asefafshar and Hamidreza Koohi "Neuro-Fuzzy Modeling of Superheating System of a Steam Power Plant" Applied Mathematical Sciences, Vol. 1, 2007, no. 42, 2091 - 2099

[13]. Rong Panxiang, Sun Jianpeng, Liu Zhaoyu, Yu Lin and Dong Wenbo "Simulation and Research of Boiler Combustion Process Based On the Improved RBF Neural Network" International Journal of $\mathrm{u}$ - and e- Service, Science and Technology ,Vol.6, No.5, pp.79-88, 2013.

\section{BIOGRAPHIES}

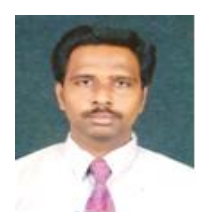

Hari Krishnan. P Was born in Madras (now Chennai). He received his $\mathrm{BE}$ degree in Electrical and Electronics of Madras University in 1997. Received his ME degree in Applied Electronics from Anna University in 2005. He is a Life member of MISTE.He is working as an assistant professor at Anna UniversityRegional Centre, Coimbatore and pursuing his research programme in the Anna University. His areas of interests include Image processing, Digital signal processing and pattern recogonition.

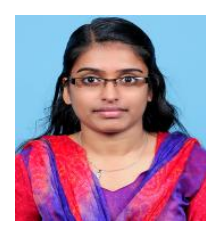

Prathyusha S was born in Shornur, Kerala, India. She received her B. Tech degree in the department of Applied Electronics \& Instrumentation Engineering from Calicut University. She is pursuing M.E degree in the department of Control \& Instrumentation

Engineering from Anna University Regional Centre, Coimbatore, India 